\title{
The Improvement in the Positioning on the Nubian and Somalia Plates by Updating Terrestrial Reference Frames
}

\author{
Farhan, M. ${ }^{1}$ and Gomaa, M. ${ }^{2}$ \\ ${ }^{1}$ Faculty of Engineering, Kafr El-sheikh University, Kafr El-sheikh, Egypt, E-mail: magdafarhan@yahoo.com \\ ${ }^{2}$ Geodynamics Department, National Research Institute of Astronomy and Geophysics, Helwan, Cairo, Egypt \\ DOI: https://doi.org/10.52939/ijg.v17i3.1891
}

\begin{abstract}
International Terrestrial Reference Frames (ITRF) is an accurate and standard frame for referencing positions at different times and in different locations around the world. The International Global Navigation Satellite System (GNSS) Service, (IGS) enable global positioning and timing at the highest possible accuracy through modernized datum's aligned with the ITRF. In addition, ITRF site velocities for any location within Africa are between 24 and $31 \mathrm{~mm} / y \mathrm{r}$ due to rigid motion of the African plate over the underlying mantle. The African plate can be divided into two Nubian and Somalia sub-plates. In the present work, the rotation rates about Euler poles and position improvement in Nubian and Somalia plates with updated ITRFs are investigated. Among the results in this study, when using a rigid plate movement and instantaneous ITRF coordinates to transform a fixed reference epoch, in case of Nubian plate, the residual in positioning and Root Mean Square Error (RMS) improved with the updating of the frame and the best results of residual and RMS appear in frame 2008 by values $(\mathbf{0 . 1 4 9 , 0 . 0 1 1 )} \mathrm{m}$. respectively but in Somali plate, residual and RMS increased with the updating of the frame and the best results appear in frame2014 by values (i.,e., 0.096, 0.012) $m$, respectively.
\end{abstract}

\section{Introduction}

For geodetic and geophysical applications (i.e., positioning, scientific research, earth rotation, plate tectonics and Precise Orbital Determination (POD), precise positions knowledge and point movement on the surface of the Earth is relevant. The International Terrestrial Reference System (ITRS) realizations have accurate geodetic station locations and speeds (Rudenko et al., 2019).Moreover, the ITRS is a spatial references device which rotates in space with the Earth in its diurnal movement. Within this system, the locations of the points related to surface of solid earth are defined as TRS by the determination of their origin, inclination axes and magnitude and time evolution, with coordinates little variability within time due to the geophysical effects (tectonic or tidal defects) and the terrestrial comparisons (Petit and Luzum, 2010).

The International Terrestrial Framework of Reference (ITRF) includes coordinates and the constant velocity parameters. These parameters used to interpolate or extra-plate the station coordination to an Arbitrary epoch (Drewes, 2006). The International Terrestrial Reference Frame allows accurate, absolute and relative motion of large tectonic plates. In order to meet the consumer criteria for different geodetic and geophysical applications, a corresponding and compatible Plate
Motion Model (PMM) introduced each time a new ITRF update. The truth is that the ITRF is used in regular implementation of national and continental reference systems, where a particular plate's rotational pole is often part of its description, reflects a geodetic function (Altamimi et al., 2017). The TRS is the International Terrestrial Reference System (ITRS), which approved for earth science applications. The International Earth Rotation and Reference Systems program (IERS) periodically provides and changes the relevant frames or ITRFs (Collilieux et al., 2011).The available realization which will be used in this paper are ITRF2005, ITRF2008 and ITRF2014.

In the practical implementation of ITRS, GNSS methodology plays a very important role. This is due to the large number of stations spread all over the world that turn this geodetic technique into a leading contribution through local connections with other geodetic spatial techniques. The GNSS system can also be used to accurately determine the ITRF orientation in space (in relation to the celeste framework) and to track their adjustments, and for the direct and exact calculation of the pole movement (Figurski and Nykiel, 2017). Precise Point Positioning (PPP) is the positioning method, which uses the widely and readily available GNSS 
products such as the International GNSS Service (IGS) to perform point positioning with one single GNSS receiver. The PPP methods vary in that differential technics require the identification of one or more referring stations with defined coordinates to which the Differential GNSS (DGNSS) positioning methods are based (Grinter and Roberts, 2011). CSRS-PPP is an online application for GNSS information that permits clients to accomplish huge enhancements in position precision (meters to centimeters). The application is a post-handling instrument that utilizes exact GNSS data (satellite ephemerides: circle and clock data) to deal with customer information. CSRS-PPP will utilize the best accessible satellite ephemeris data accessible for the time-frame at which the client information was gathered (Klatt and Johnson, 2017).The surface of the Earth consists of a variety of tectonic plates. Such plates collide at speeds of up to a range of centimeters a year, break or slide through adhering plate margins.

Tectonic plates are generally rigid internally and stable from the boundaries of the plate. It is doubtful that baselines between any two geologically and structurally sound geodetic stations on a rigid plate would shift by more than a few $\mathrm{mm} /$ year (Stanaway and Roberts, 2009). Space geodetic techniques have been precise enough for estimating site acceleration (i.e. site speed) on the surface of the Earth directly over the past 20 years. Instantaneous (on a geologic time scale) plate movement models (actual) determine the reversal of these location speeds. (Sella et al., 2002, Bird, 2003, Kreemer et al., 2006, Altamimi et al., 2007 and Drewes, 2006). Therefore, a simpler transformation technique from a plate rotation model can be built for instantaneous ITRF coordinate to the data in many regions in which a geodetic data is coupled with a solid tectonic base or stable block.

The plate of Africa consists of two different plates, which separated into Nubia to the west and Somalia to the east along the East African Rift network. One of the recent advances in plateboundary kinematics is the discovery of the variations between Somalia and Nubian plates in the East African Rift System (EARS). The most comprehensive geodetic study to date (Saria et al., 2014) indicates a slow, clockwise rotation of the Somalia plate with respect to Nubian about a pole located offshore South Africa. ITRF frames used certain points which do not represent all points within the plates. By using conversion parameters of plates, we can test the most suitable frame for the position of all points. The presence of different geodetic datums (ITRF 2005, ITRF2008 and ITRF2014) gives the necessity to test the improvement of positioning accuracy with the different datums. The current work tests the improvement of accuracy in the Nubian and Somalia positioning, based on a set of GNSS data, with updated ITRF frames.

\section{Data Collection}

In order to study the improvement in the positioning on the Nubian and Somalia plates by updating frames. Thirteen permanent stations of one day have been divided to 2 groups: 5 points for Somalia plate and 8 points for Nubian as Table 1, Figure1. The IGS points were downloaded through the site SOPAC Data Browser (Http://SopacOld.Ucsd.Edu/DataBrowser.Shtml, n.d.). The downloaded observations processed using Canadian Spatial Reference System Precise Point Positioning (CSRS-PPP) Service. Also, the coordinates of the selected points are defined in ITRF2005, ITRF2008, and the latest frame ITRF2014 given and published by the IERS (http://itrf.ign.fr/ITRF_solutions/index.php). The absolute plate rotation poles of Somalia and Nubian plates related to updating frames have been calculated using (Matlab software to estimate Euler Pole parameters) EPC MATLAB software.

\section{Methodology}

To study the extent of improvement in the position on the Nubian and Somalia plates by updating frames, we calculated the positions of the selected IGS stations at different epochs. After that, we calculated the positions for the same stations at reference epochs for ITRF datums. Finally, we compare the obtained positions with the published one from ITRF services to choose the most accurate datum for Nubian and Somalian Plates. The work done by fifth stages as follow:

- First Stage: IGS points selected on Nubian and Somalia plates were processed by CSRSPPP Service based on utilizing Precise Point Positioning "PPP", related to International Terrestrial Reference Frame 2014 (ITRF2014). List of used IGS stations and date of observations shown in Table 1.

- Second Stage: The second stage includes calculation of the rotation parameters of Nubian and Somalia plates.

According to (Altamimi et al., 2007, 2012 and 2017) tectonic plate motion is typically defined by the axis and rate of rotation of the rigid plate about Euler pole. 
Table 1: Used IGS stations and dates of observations

\begin{tabular}{|c|c|c|c|c|c|}
\hline Nubian Points & Date & DOY & Somalia Points & Date & DOY \\
\hline DAKA & $30 / 05 / 2005$ & 2005.41 & REUN & $1 / 11 / 2019$ & 2019.835 \\
\hline HARB & $01 / 01 / 2019$ & 2019.003 & SEY1 & $01 / 11 / 2013$ & 2013.835 \\
\hline NKLG & $01 / 01 / 2019$ & 2019.003 & RBAR & $01 / 03 / 2019$ & 2019.164 \\
\hline SUTH & $30 / 01 / 2018$ & 2018.082 & MBAR & $01 / 11 / 2019$ & 2019.835 \\
\hline RABT & $01 / 01 / 2019$ & 2019.003 & MALI & $30 / 05 / 2005$ & 2005.41 \\
\hline MAS1 & $01 / 01 / 2019$ & 2019.003 & & & \\
\hline SIMO & $31 / 05 / 2009$ & 2009.041 & & & \\
\hline ZAMB & $30 / 11 / 2018$ & 2018.915 & & & \\
\hline
\end{tabular}

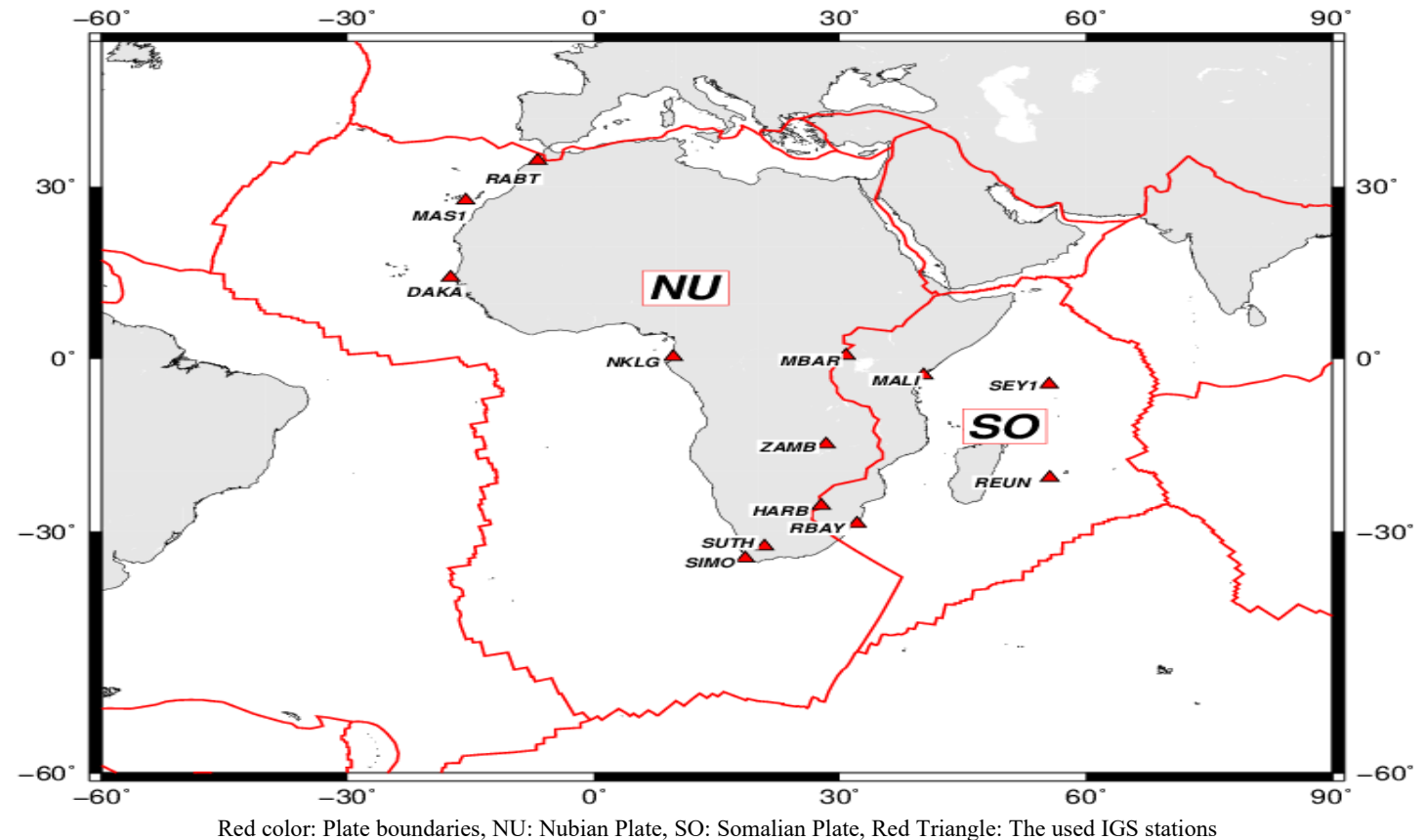

Figure 1: Used IGS stations located in Nubian and Somalia plates

The tectonic plate motion along the earth's surface described by Euler's rotation theorem in spherical geometry. According to the theorem, the movement of a rigid body across a sphere surface can be modeled as a rotation around an axis of rotation, which cross the sphere center. The rotation pole is one of the two points where that axis intersects the sphere surface (Lowrie, 2007). Geophysical application of this theorem indicates that the movement of a tectonic plate relative to other plates happened as a rotation about the Euler pole between the plates.

From velocities and coordinates of ITRF, EPC (Goudarzi et al., 2013) has been used to calculate the origin and angular velocity for Nubian and Somalia plates. Euler pole calculator (EPC) software developed at the Center for Research in Geomatics (CRG), Laval University, Canada, to determine both (1) the horizontal velocities of any point on the earth's surface from the Euler pole parameters and (2) the Euler pole parameters by using the observed velocities at a set of measuring sites on the earth's surface located on the same rigid tectonic block. The Euler theorem can be formulated as:

$$
V_{i}^{p}=\Omega^{p} \times X_{i}=\left[\begin{array}{ccc}
0 & -\omega_{z} & \omega_{y} \\
\omega_{z} & 0 & -\omega_{x} \\
-\omega_{y} & \omega_{x} & 0
\end{array}\right]^{p}\left[\begin{array}{l}
x \\
y \\
z
\end{array}\right]_{i}
$$

Equation 1

Where $V_{i}^{p}$ and $X_{i}\left(x_{i}, y_{i}, z_{i}\right)^{T}$ are the velocity and the position of the stationi, and $\Omega^{p}\left(\omega_{x}^{p}, \omega_{y}^{p}, \omega_{z}^{p}\right)$ is the angular velocity or the Euler vector of the plate $p$ associated with the station $i$. The label $\mathrm{p}$ in the model refers to the assumed plate and does not represents the reference frame. 
The cross product taken between the angular velocity vector and the station position vector in an Earth-Centered Earth-Fixed Cartesian Coordinate System (ECEF CCS). Therefore, the velocity $V_{i}^{p}$ is also expressed in the ECEF CCS. The magnitude of the Euler vector $\Omega^{p}=\left|\Omega^{p}\right|$ is the rate of rotation of the plate $\mathrm{p}$ around its pole and is usually expressed in degrees per million years $(\% / \mathrm{Myr})$. The direction of the Euler vector $\widehat{\Omega^{p}}=\Omega^{p} /\left|\Omega^{p}\right|$ is called the "Euler pole" and is often terminated as a spherical latitude and longitude in degrees. In this rotation model, the plate $\mathrm{p}$ is constrained to move rigidly on the spherical earth's surface without radial motion. Equation 1 can be rewrite using basic skewsymmetric matrix properties (Liu and Trenkler 2008) as follows:

$$
V_{i}^{p}=\left[\begin{array}{ccc}
0 & z & -y \\
-z & 0 & x \\
y & -x & 0
\end{array}\right]_{i}\left[\begin{array}{c}
\omega_{x} \\
\omega_{y} \\
\omega_{z}
\end{array}\right]^{p}=\Omega^{p} \times X_{i}
$$

Equation 2

The new form of equation (1) may simplify calculations of the Euler theorem and it will be a basic formula for developing models. From equation (2), we calculate the Euler pole parameters by inverting the ITRF velocity vectors of a set of points located on Nubian and Somali plates. The calculated Latitude, Longitude, and angular velocity for Nubian and Somalia plates shown in the Table 2. Latitude and longitude of the Euler pole has been considered while describing the rotation, $\Omega \mathrm{X}, \Omega \mathrm{Y}$, and $\Omega Z$ are earth's rotation of rigid (radiation $/ 10^{\wedge} 6$ years) as shown in the following equations:

$$
\begin{gathered}
\Omega_{X}=\cos (\text { lat. }) \cos (\text { long. }) \omega \\
\Omega_{Y}=\cos (\text { lat. }) \sin (\text { long }) \omega \\
\text { Equation } 3 \\
\Omega_{Z}=\sin (\text { lat. }) \omega
\end{gathered}
$$

Equation 5

- Third Stage: the third stage contains the propagation of the transformed coordinates to the reference epoch of each datum.

By using the formula which introduced by (Altamimi et al., 2007) in which an epoch has been used as a reference $\left(t_{i, j, k}\right)$ when another one $\left(t_{t}\right)$ is measured. The ITRF for the selected set of points of Somalia and Nubian plates which are shown in Table 3 at $\mathrm{X}_{0}, Y_{O}, Z_{O}(\mathrm{~m})$ as reference epoch are estimated using $\mathrm{t}(X t, Y t, Z t)$ in meters) as a coordinates epoch based on equation (6):

$\left[\begin{array}{c}X_{0} \\ Y_{0} \\ Z_{0}\end{array}\right]=\left[\begin{array}{c}T_{X} \\ T_{Y} \\ T_{Z}\end{array}\right]+S \cdot\left[\left[\begin{array}{c}X_{t} \\ Y_{t} \\ Z_{t}\end{array}\right]+\left[\begin{array}{c}\Omega_{Y} Z_{t}-\Omega_{Z} Y_{t} \\ \Omega_{Z} X_{t}-\Omega_{X} Z_{t} \\ \Omega_{X} Y_{t}-\Omega_{Y} X_{t}\end{array}\right] \cdot\left(t_{i, j, k}-t_{t}\right) / 1000000\right]$

Equation 6

$\left(X_{0}, Y_{0}, Z_{0}\right)$ are the ITRF Cartesian coordinates at the reference epoch $t_{i, j, k} i, j, k$ are epochs of

\begin{tabular}{|c|c|c|c|c|c|c|}
\hline $\begin{array}{l}\text { Nubian } \\
\text { Plate }\end{array}$ & lat., deg & long., deg & $\begin{array}{l}\omega, \text { deg } \\
/ \mathbf{m} . \mathbf{y} .\end{array}$ & $\Omega_{X}(\operatorname{Rad} / \mathbf{M a})$ & $\Omega_{Y}(\operatorname{Rad} / \mathbf{M a})$ & $\boldsymbol{\Omega}_{Z}(\mathbf{R a d} / \mathbf{M a})$ \\
\hline ITRF2005 & $\begin{array}{l}49.6412 \\
\pm 1.6412\end{array}$ & $\begin{array}{l}-82.6076 \\
\pm 4.42\end{array}$ & $\begin{array}{l}0.26791 \\
\pm 0.0073 \\
\end{array}$ & 0.0003893959 & -0.003001299 & 0.00356125 \\
\hline ITRF2008 & $\begin{array}{l}49.3753 \\
\pm 0.543\end{array}$ & $\begin{array}{l}-81.0622 \\
\pm 1.644\end{array}$ & $\begin{array}{l}0.26691 \\
\pm 0.0028\end{array}$ & 0.00047009945 & -0.00299478 & 0.0035333934 \\
\hline ITRF2014 & $\begin{array}{l}49.3307 \\
\pm 0.428\end{array}$ & $\begin{array}{l}-81.7683 \\
\pm 1.314\end{array}$ & $\begin{array}{l}0.26618 \\
\pm 0.0022\end{array}$ & 0.0004332582 & -0.002994865 & 0.00352191 \\
\hline $\begin{array}{l}\text { Somalia } \\
\text { Plate }\end{array}$ & lat., deg & long., deg & $\begin{array}{l}\omega, \text { deg } \\
\text { /m.y. }\end{array}$ & $\Omega_{X}(\operatorname{Rad} / \mathbf{M a})$ & $\Omega_{Y}(\operatorname{Rad} / \mathrm{Ma})$ & $\mathbf{\Omega}_{Z}(\mathbf{R a d} / \mathbf{M a})$ \\
\hline ITRF2005 & $\begin{array}{l}51.0664 \\
\pm 5.7884 \\
\end{array}$ & $\begin{array}{l}-92.4469 \\
\pm 10.657 \\
\end{array}$ & $\begin{array}{l}0.31993 \\
\pm 0.03892 \\
\end{array}$ & -0.0001497 & -0.003504 & 0.0043413 \\
\hline ITRF2008 & $\begin{array}{l}49.9031 \\
\pm 3.1171\end{array}$ & $\begin{array}{l}-94.4751 \\
\pm 5.3364\end{array}$ & $\begin{array}{l}0.3220 \\
\pm 0.02172\end{array}$ & -0.00028228 & -0.00360685 & 0.00429684 \\
\hline ITRF2014 & $\begin{array}{l}46.2184 \\
\pm 5.409\end{array}$ & $\begin{array}{l}-98.2868 \\
\pm 8.1089\end{array}$ & $\begin{array}{l}0.34179 \\
\pm 0.04447\end{array}$ & -0.00059458 & -0.00408233 & 0.0043047 \\
\hline
\end{tabular}
ITRF2005, ITRF2008, and ITRF2014 (2000, 2005 and 2010) respectively. $\left(X_{t}, Y_{t}, Z_{t}\right)$ are instantaneous ITRF Cartesian coordinates at epoch of observation $t_{t}$.

Table 2: Computed Cartesian axes in radians per million year's values of Somalia and Nubian plates 
For any ITRF aligned realization the translation $\left(T_{X}, T_{Y}, T_{Z}\right)$ and scale(S) components are zero and one respectively.

$P_{i} \quad:$ is the resultant vector of residual

$P_{i}^{-} \quad$ in position.

: The arithmetic mean of the resultant vector of the residual in position equal $\frac{\sum P_{i}}{n}$

$i \quad:$ is the number of residuals in position vector, $\mathrm{i}$ from 1 to $\mathrm{n}$ $=8$ at case of Nubian, 5 at case of Somalia Plates

$d x, d y, d z \quad$ : are the residual in $\mathrm{x}, \mathrm{y}, \mathrm{z}$ directions (differences between calculated and published coordinates)

$V_{i} \quad:$ The residual in positioning

R.M.S : Root Mean Square errors

- Fourth Stage is comparing results obtained from our calculations with the published coordinates of the selected points in ITRF2005, ITRF2008 and ITRF2014.

According to the results of coordinates related to ITRF 2005, 2008 and 2014 at their reference epochs by using computed Cartesian axes of Somalia and Nubian plates. The residual of Positioning vector (P) and Root Mean Square Errors are computed by the following equations:

$$
\begin{gathered}
P_{i}=\sqrt{d x_{i}^{2}+d y_{i}^{2}+d z_{i}^{2}} \\
V_{i}=\left(P_{i}-P_{i}^{-}\right)
\end{gathered}
$$

Equation 7

Equation 8

$$
\text { R.M.S }=\sqrt{\frac{\left(\sum V^{2}\right)}{n-1}}
$$

Equation 9

Where:

- Fifth Stage: Compare between the results in all cases.

By comparing between the position residual values and Root Mean Square Error of two plates related the updating frames.

\section{Results and Discussion \\ 4.1 Nubian Plate}

Figure 2 and Table 3 illustrate the coordinates differences in $\mathrm{X}, \mathrm{Y}, \mathrm{Z}$ between calculated and published Nubian points related to ITRF2005, ITRF2008 and ITRF2014. The difference is significantly reduced in the case of Frame ITRF2008 and ITRF2014 compared to Frame ITRF2005. In addition, differences for ITRF2008 and ITRF2014 are very close to each other. Although, differences for ITRF2008 are the smallest. SIMO point show high differences in $d x, d y, d z$ which due to its highly active deformation behavior. From Figures 3 and 4, when calculating the residual of positioning vector and RMS for all selected points on Nubian plate, residual of positioning shows that ITRF2008 is the most suited frame. In addition, the RMS decreased in ITRF2008 and ITRF2014 with smallest values in ITRF2008. Moreover, verification by calculating the values of Root Mean Square Errors related three frames recording $(0.0116,0.0113,0.0152) \mathrm{m}$ respectively has been calculated and showed in Figure 4. Significantly improvement of accuracy with the updating of the frame can be noticed, whereas accuracy improves in Frame 2008 compared to

\begin{tabular}{|c|c|c|c|c|c|c|c|c|c|}
\hline \multirow{2}{*}{$\begin{array}{c}\text { Nubian } \\
\text { Plate } \\
\text { Points } \\
\end{array}$} & \multicolumn{3}{|c|}{ ITRF 2005 EPOCH 2000} & \multicolumn{3}{|c|}{ ITRF 2008 EPOCH2005 } & \multicolumn{3}{|c|}{ ITRF 2014 EPOCH2010 } \\
\hline & $d x$ & $d y$ & $d z$ & $d x$ & $d y$ & $d z$ & $d x$ & Dy & $d z$ \\
\hline DAKA & 0.032 & -0.011 & -0.009 & 0.002 & -0.011 & 0.008 & 0.001 & -0.012 & 0.013 \\
\hline HARB & -0.005 & 0.003 & 0.006 & 0.000 & 0.004 & -0.007 & -0.005 & 0.005 & 0.002 \\
\hline NKLG & -0.011 & -0.006 & 0.004 & 0.000 & 0.000 & -0.001 & -0.001 & 0.002 & 0.000 \\
\hline SUTH & 0.007 & 0.002 & 0.009 & 0.007 & 0.002 & -0.002 & 0.007 & 0.004 & 0.001 \\
\hline RABT & -0.005 & -0.001 & -0.017 & -0.015 & 0.005 & -0.019 & -0.010 & 0.006 & -0.012 \\
\hline MAS1 & -0.034 & 0.017 & -0.004 & -0.024 & 0.018 & -0.008 & -0.012 & 0.018 & 0.006 \\
\hline SIMO & -0.018 & -0.020 & 0.018 & 0.023 & 0.008 & -0.018 & 0.041 & 0.009 & -0.029 \\
\hline ZAMB & 0.014 & -0.001 & 0.007 & 0.010 & 0.003 & -0.002 & 0.012 & 0.007 & 0.000 \\
\hline
\end{tabular}
Frame 2005 and Frame 2014.

Table 3: Coordinates differences between calculated and published related to frames updating 


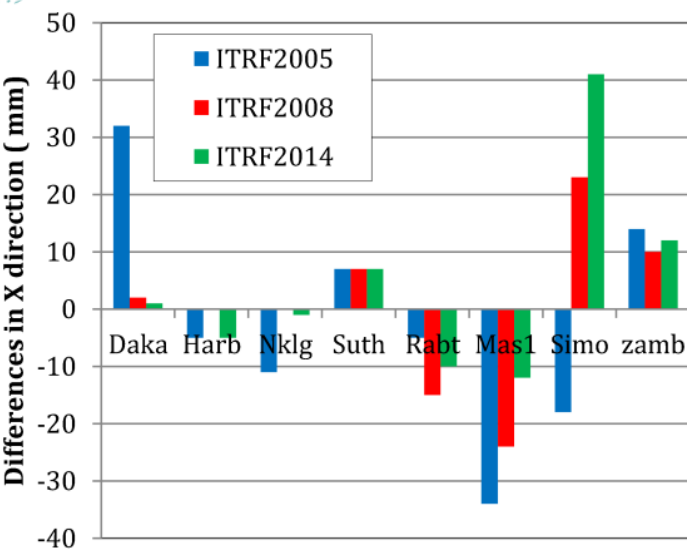

(a)

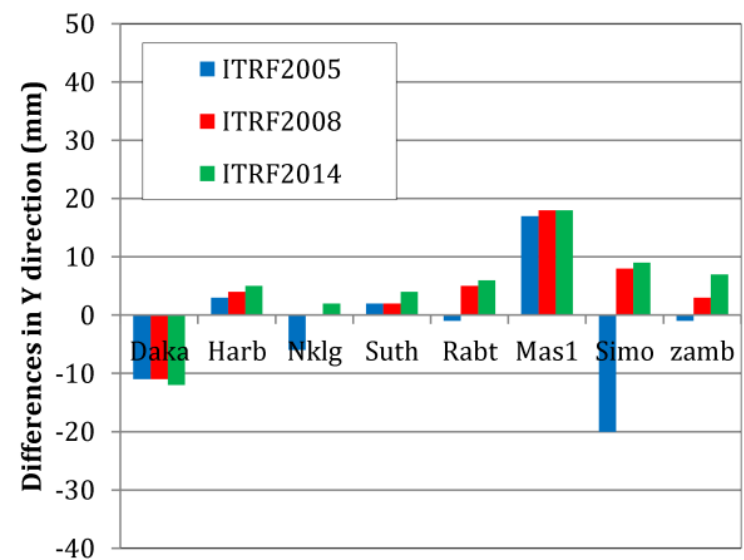

(b)

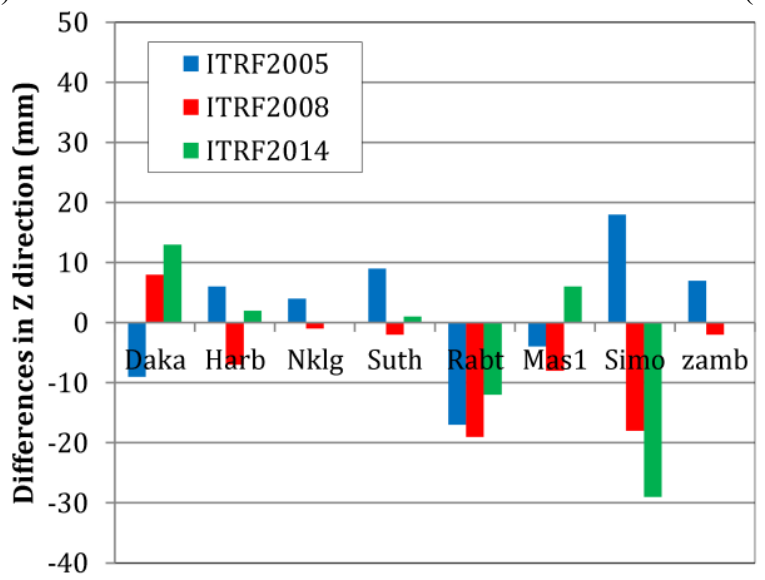

(c)

Figure 2: Differences between calculated positions and ITRFS positions at Nubian plate (a) in X Direction, (b) in Y Direction and (c) in Z Direction

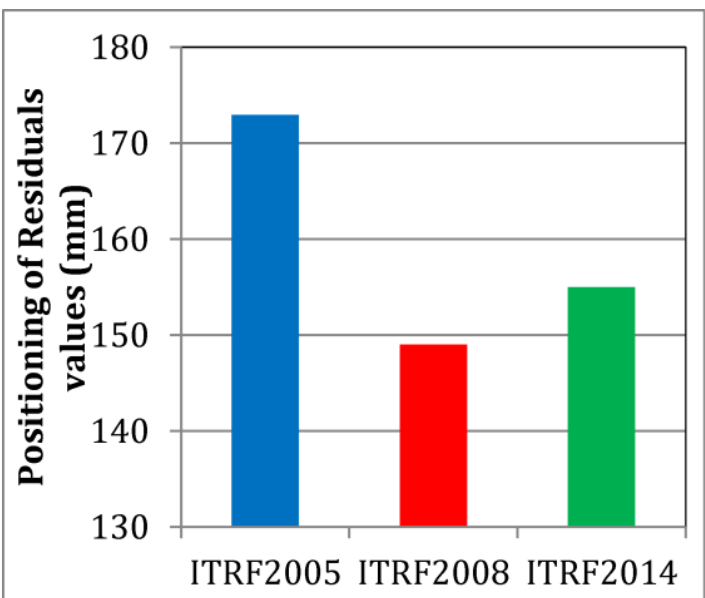

Figure 3: Residual of positioning Improvements in Nubian points related updating frames

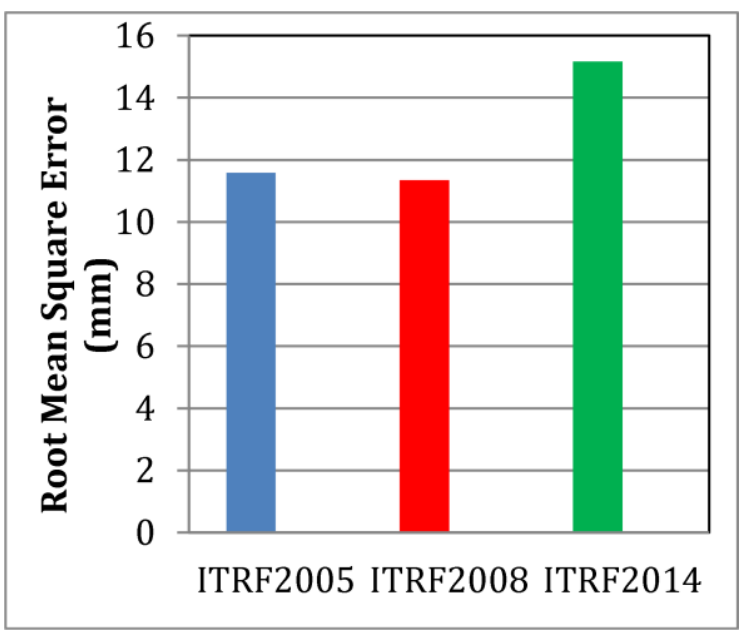

Figure 4: Root Mean Square Error related to updating frames on Nubian plate 
Table 4: Coordinates differences between calculated and published related to frames updating

\begin{tabular}{|l|l|l|l|l|l|l|l|l|l|}
\hline \multirow{2}{*}{$\begin{array}{c}\text { Somalia } \\
\text { Plate Points }\end{array}$} & \multicolumn{3}{|l|}{ ITRF 2005 EPOCH 2000 } & \multicolumn{3}{l|}{ ITRF 2008 EPOCH2005 } & \multicolumn{2}{|l|}{ ITRF 2014 EPOCH2010 } \\
\cline { 2 - 11 } & $\boldsymbol{d} \boldsymbol{x}$ & $\boldsymbol{d} \boldsymbol{y}$ & $\boldsymbol{d} \boldsymbol{z}$ & $\boldsymbol{d} \boldsymbol{x}$ & $\boldsymbol{d} \boldsymbol{y}$ & $\boldsymbol{d} \boldsymbol{z}$ & $\boldsymbol{d} \boldsymbol{x}$ & $\boldsymbol{D} \boldsymbol{y}$ & $\boldsymbol{d} \boldsymbol{z}$ \\
\hline REUN & 0.015 & -0.040 & 0.017 & 0.006 & -0.016 & 0.006 & -0.001 & -0.007 & 0.006 \\
\hline SEY1 & -0.006 & -0.032 & 0.001 & 0.001 & -0.014 & -0.002 & 0.004 & -0.001 & 0.001 \\
\hline RBAR & 0.012 & -0.046 & -0.006 & 0.003 & -0.024 & -0.008 & -0.009 & -0.008 & -0.017 \\
\hline MBAR & 0.044 & -0.040 & -0.019 & 0.016 & -0.031 & -0.019 & 0.015 & -0.013 & -0.027 \\
\hline MALI & 0.019 & 0.010 & 0.001 & 0.017 & 0.011 & -0.001 & 0.021 & 0.018 & 0.007 \\
\hline
\end{tabular}

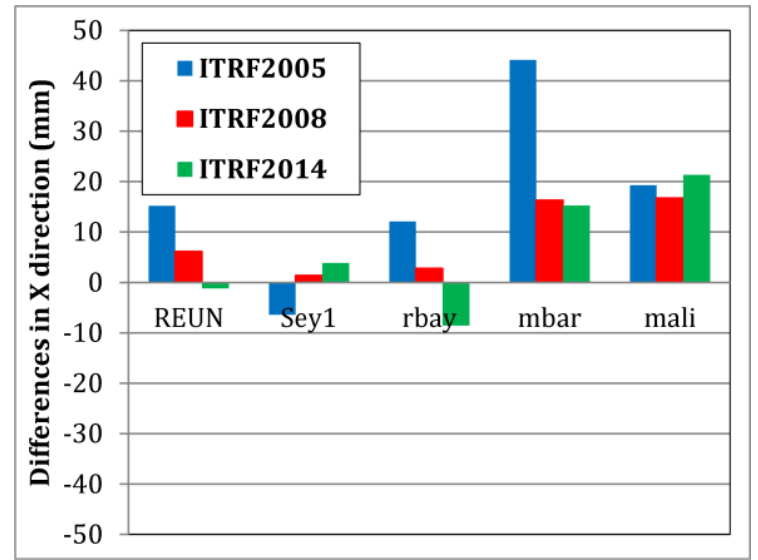

(a)

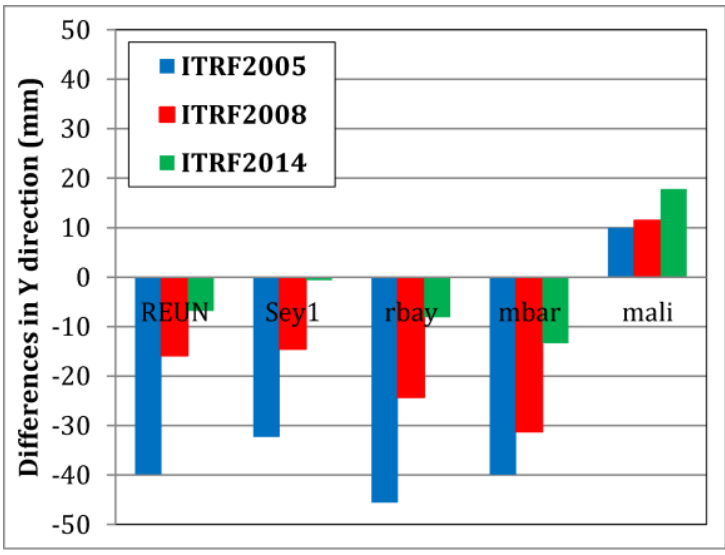

(b)

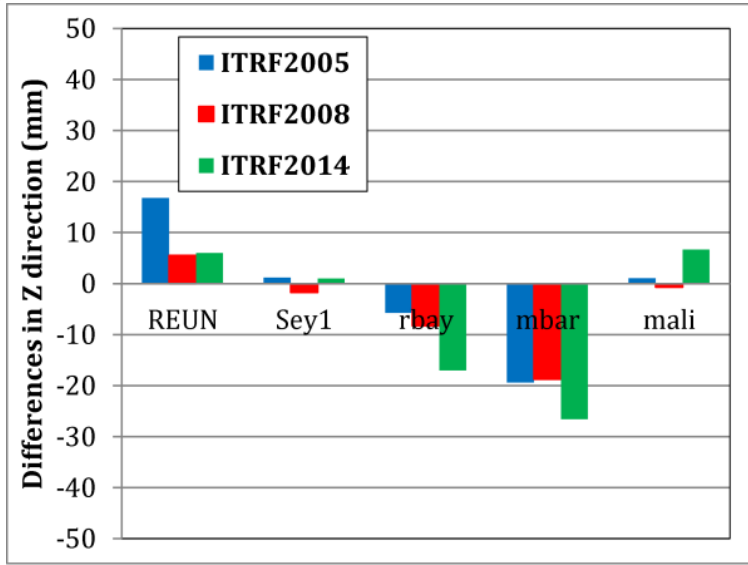

(c)

Figure 5: Differences between calculated positions and ITRFS positions at Somalia plate (a) in X Direction, (b) in Y Direction and (c) in Z Direction

\subsection{Somalia Plate}

The results in the case of the Somalia plate refer that difference in $d x, d y$ improved with update ITRF frame. On the other hand, there is no such improvement in case of $d z$. In addition, MBAR point shows significant differences, which may due to presence of the point in the border between the Nubian and Somalia plates (Table 4). Significant differences at MBAR indicate a local deformation in both horizontal and vertical directions. In addition, calculated the residual of positioning for points in Somalia plate indicate the improvement in the residual of positioning with updated frame, where ITRF2014 shows lowest values of the residual of positioning (Figures 5 and 6). The previous confirmation is achieved when calculating the Mean Square Errors. Figure 7 shows that the accuracy improved with a frame update. Whereas the Root Mean Square Error values were calculated for each of Frames 2005, 2008and2014 recording (0.016, $0.010,0.012) \mathrm{m}$. respectively. ITRF2008 represents the most accurate frame for Somalia plate and also are very close to ITRF2014. 
4.3 Comparison between the Results of Positioning in all Cases

To compare between the residual of positioning values of two plates related the updating frames, the residuals of positioning are computed in all cases, Figure 8 clearly shown from the values of the residual of positioning in different frame are $(0.173$, $0.149,0.155)$ meters related to ITRF2005, ITRF2008 and ITRF2014 respectively, the residuals of positioning improve by updating the frame in case of Nubian plate, especially at ITRF2008. In case of Somalia plate, clearly evident from the residuals of positioning values, are $(0.211,0.118$, 0.096) $\mathrm{m}$. related the previous frames, notice that the residuals of positioning values related frame 2014 is much better compared frame 2005 and frame 2008 see Figure 8.

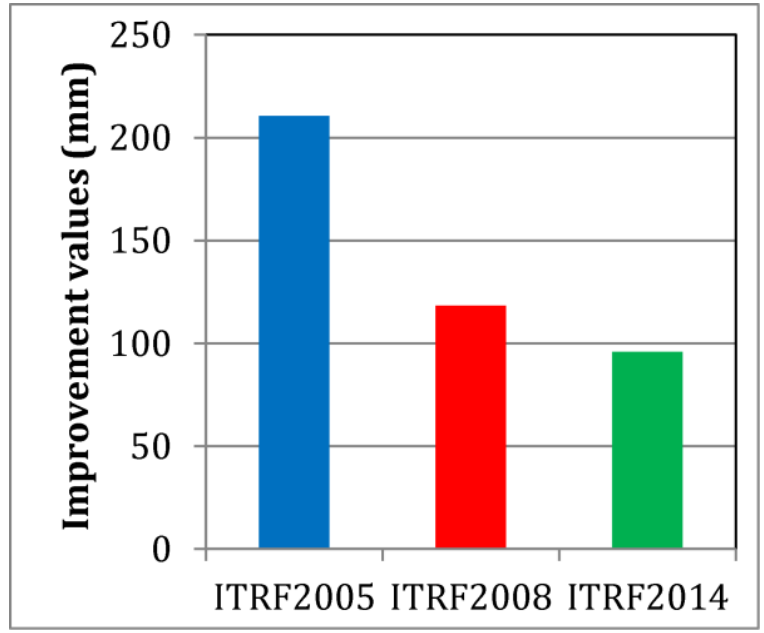

Figure 6: Residual of positioning improvements in Somalia points related updating frames

\section{Conclusion}

In this study, thirteen permanent stations form Nubian and Somalia plates have been procced. The rotation parameters for both Somalia and Nubian plates and three frames (ITRF2005, ITRF2008, and ITRF2014) were calculated and the improvement in the positioning on the Nubian and Somalia plates by updating frames were investigated. According to the results comparing with ITRF2005, an improvement in the residual of positioning and RMS has been noticed by updating the frame for Nubian and Somalia plate in ITRF2008, ITRF2014. In some points, which suffer from local deformation as SIMO and MBAR, the differences still significant even with updating frame.

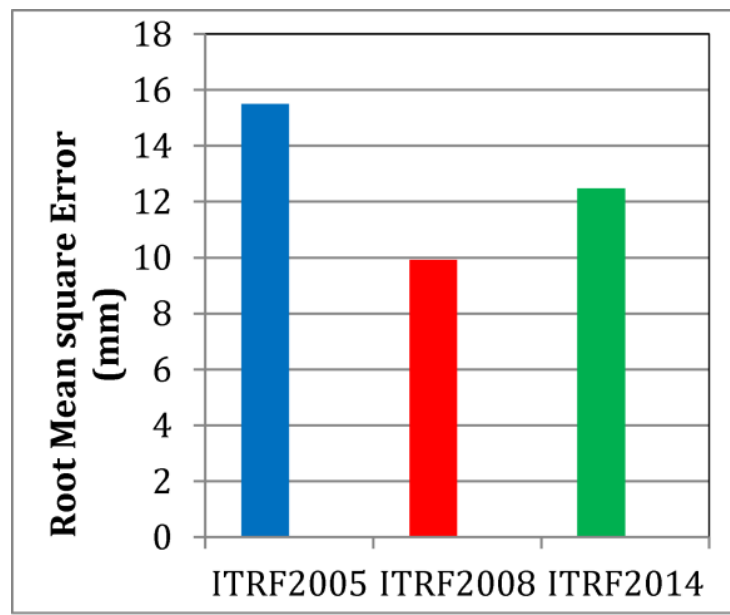

Figure 7: Root mean square error related to updating frames on Somalia plate

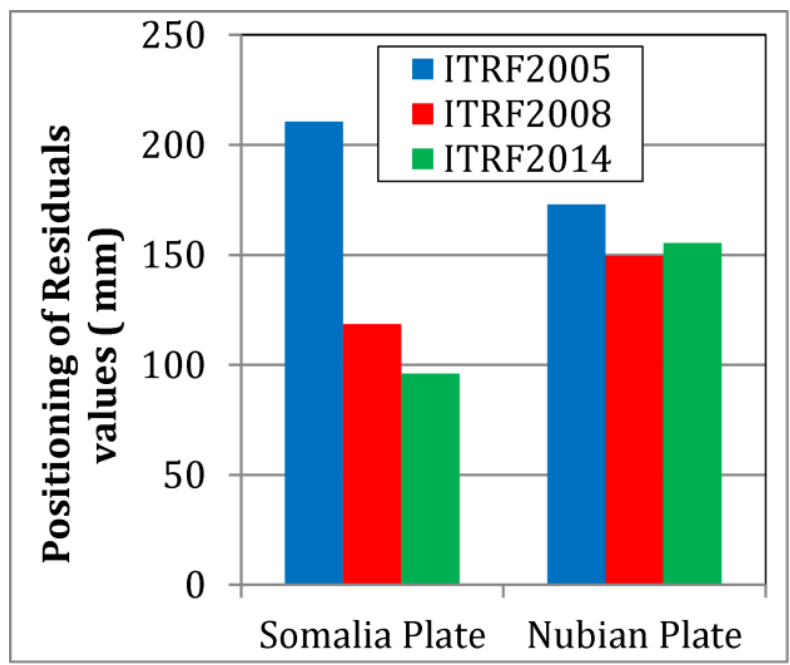

Figure 8: Residual of positioning improvement in Nubian and Somalia plates related to updating frames 
The calculated the residual of positioning and RMS for selected points support the idea of improvement of position with updated frame. However, ITRF2008 is the most fitted frame for Nubian plate and ITRF2014 for Somalia plate. We can conclude that update frame improves the positioning accuracy of GNSS stations, but we have to take into consideration the local movements for these stations. In addition, the Somalian plate has small number of IGS stations, which have to be increased to get more accurate and represented plate motion. Moreover, The ITRF2014 is not fit for all plates as case of Nubian Plate. Therefore, the ITRF2014 has to be updated by adding more geodetic observations.

\section{References}

Altamimi, Z., Collilieux, X., Legrand, J., Garayt, B. and Boucher, C., 2007, ITRF2005: A New Release of the International Terrestrial Reference Frame Based on Time Series of Station Positions and Earth Orientation Parameters. Journal of Geophysical Research: Solid Earth, Vol. 112(9). https://doi.org/10.1029/2007JB004949.

Altamimi, Z., Métivier, L. and Collilieux, X., 2012, ITRF2008 Plate Motion Model. Journal of Geophysical Research: Solid Earth, Vol. 117(7), 1-14. https://doi.org/10.1029/2011JB008930.

Altamimi, Z., Métivier, L., Rebischung, P., Rouby, H. and Collilieux, X., 2017, ITRF2014 Plate Motion Model. Geophysical Journal International, Vol. 209(3), 1906-1912. https://doi.org/10.1093/gji/ggx136.

Bird, P., 2003, An Updated Digital Model of Plate Boundaries. Geochemistry, Geophysics, Geosystems, Vol. 4(3). https://doi.org/10.1029/2001GC000252.

Collilieux, X., Métivier, L., Altamimi, Z., van Dam, T. and Ray, J., 2011, Quality Assessment of GPS Reprocessed Terrestrial Reference Frame. GPS Solutions, Vol. 15(3), 219-231. https://doi.org/10.1007/s10291-010-0184-6.

Drewes, H., 2006, Geodetic Reference Frames IAG Symposium, Munich, Germany, October 914, IAG Symposia, Vol. 134, Springer, 10.10071978-3-642-00860-3, 2009.

Figurski, M. and Nykiel, G., 2017, Investigation of the Impact of ITRF2014/IGS14 on the Positions of the Reference Stations in Europe. Acta Geodynamica et Geomaterialia, Vol. 14(4), 401-410. https://doi.org/10.13168/AGG.2017. 0021.
Grinter, T. and Roberts, C., 2011, Precise Point Positioning: Where are we now? Proc. IGNSS2011, Sydney, Australia, 15-17 November, 15pp. (e.g. accessible from http://www.ignss.org/Conferences/PastPapers/ta bid/64/Default.aspx).

Klatt, C. and Johnson, P., 2017, Estimating Benefits to Canada and the World: The Canadian Spatial Reference System Precise Point Positioning Service. Geomatica, Vol. 71(1), 37-44. https://doi.org/10.5623/cig2017-104.

Kreemer, C., Lavallée, D. A., Blewitt, G. and Holt, W. E., 2006, On the Stability of a Geodetic NoNet-Rotation Frame and its Implication for the International Terrestrial Reference Frame. Geophysical Research Letters, Vol. 33(17). 115, https://doi.org/10.1029/2006GL027058.

Lowrie, W., 2007, Fundamentals of geophysics. Cambridge University Press, New York.

Mohammad Ali Goudarzi, Marc Cocard, and Rock Santerre 2013, EPC: Matlab software to estimate Euler pole parameters. GPS Solutions, Vol. 18, Number 1 (published online: 22 November 2013), DOI: 10.1007/s10291-013-0354-4.

Petit, G. and Luzum, B., 2010, IERS Conventions (2010), IERS Technical Note 36. Verlagdes Bundesamts Für Kartographie Und Geodäsie, 31-42.

Rudenko, S., Esselborn, S., Schöne, T. and Dettmering, D., 2019, Impact of Terrestrial Reference Frame Realizations on Altimetry Satellite Orbit Quality and Global and Regional Sea Level Trends: A switch from ITRF2008 to ITRF2014. Solid Earth, Vol. 10(1), 293-305. https://doi.org/10.5194/se-10-293-2019.

Saria, E., Calais, E., Stamps, D. S., Delvaux, D. and Hartnady, C. J. H., 2014, Solid Earth Presentday kinematics of the East African Rift. Journal of Geophysical Research, Vol. 119, 1-17. https://doi.org/10.1002/2013JB010901.

Sella, G. F., Dixon, T. H. and Mao, A., 2002, REVEL: A Model for Recent Plate Velocities from Space Geodesy. Journal of Geophysical Research: Solid Earth, Vol. 107(B4), ETG 11-1ETG 11-30. https://doi.org/10.1029/2000jb000033.

Stanaway, R. and Roberts, C., 2009, A Simplified Parameter Transformation Model from ITRF2005 to any Static Geocentric Datum ( e . g .GDA94 ). International Global Navigation Satellite Systems Society IGNSS Symposium. 115. 